\title{
Understanding PhD Latinx Career Outcomes: A Case Study
}

\author{
Mark Kamimura-Jimenez \\ Rackham Graduate School \\ Director for Graduate Student Success 915 E. Washington St. \\ Ann Arbor, Ml 48109-1070 \\ Email: mkamimur@umich.edu \\ Phone: (734) 717-2605 \\ John Gonzalez \\ Director of Institutional Research \\ Rackham Graduate School \\ University of Michigan $915 \mathrm{E}$. Washington St. \\ Ann Arbor, Ml 48109-1070 \\ Email: jagonza@umich.edu \\ Phone: 734-763-7936
}




\section{Understanding PhD Latinx Career Outcomes: A Case Study}

\section{Introduction}

The rising costs of higher education and the increased demand for graduate education has complicated the market value of the PhD. In The Graduate School Mess, Leonard Cassuto examines the diminished opportunities for faculty positions that previously were more readily available upon completing the $\mathrm{PhD}$, which has increased the market competition, increased selectivity and shifted expectations of achievements for recent graduates entering academia. This growing debate on the value of the $\mathrm{PhD}$ is at odds with the need for increased representation of Latinxs in higher education, specifically increasing the number of Latinxs in graduate education, attaining $\mathrm{PhDs}$, and pursuing the professoriate. However, increased need for Latinx doctorates does not change the market competition for academic positions and therefore Latinx PhDs also seek other career pathways in industry and the nonprofit sector.

The path to a career in and out of the academy is extraordinarily complex, however, a closer look at the graduate experience through a case study will explore a variety of potentially influential factors in the graduate experience that impact these paths. Pathways are a series of collective experiences that build on each other towards measureable outcomes, in this case, career outcomes. As a part of this study, the institutional activities that contextualize these experiences and the career pathway are important to describe and understand as facilitating factors in career outcomes. Some of these activities included students' access to resources during their doctoral program, to professional development, mentoring, advising and other student programs aimed at increasing success during and after graduate school.

\section{Literature Review}

To understand the outcomes of the doctoral educational experience, adequate attention needs to be given to the challenges experienced by Latina/os in higher education. The 
educational pipeline and pathway for Latinx students has indicated that there are a number of factors that contribute to the success of Latinx students along the way (Castellanos, Gloria \& Kamimura, 2006; Huber, Huidor, Malagon, Sanchez, \& Solorzano, 2006). In addition, for Latinx graduate students, some of these factors begin with early access programs that opened pathways from high school to college (e.g., Talent Search, Upward Bound, Gear Up, Early Outreach Program and Summer Bridge) and from college to graduate school (e.g., Summer Research Opportunity Program, Ronald E. McNair Scholars, Louis Stokes Alliance for Minority Participation and Institute for the Recruitment of Teachers). At the end of this journey, Latinx students earned $7.2 \%$ of domestic doctorates compared to $69.3 \%$ for Whites, and this disparity is even greater when looking at degree completion within subfields (Rochin \& Mello, 2007; NCES, 2016).

The Latinx educational path is grounded in the development of mentoring relationships. Mentorship is important for Latinx students because of the lack of representation of Latinx faculty and staff on our college campuses (Haro, 2004). Latinx faculty across the country is only represented $4 \%$ compared to $78 \%$ of Whites, and approximately $5 \%$ of all full time-college administrators are Latinx, the majority are employed in positions classified as being of moderate to low prestige (Haro \& Francisco, 2003; NCES, 2013, Ramirez, 2017). Therefore, the role of mentorship for Latinx graduates is largely sought out through informal mentoring relationships, then formal relationships and only a small percentage of these roles filled by other Latinx leading to a high number of cross-ethnic mentoring (Schueths \& Carranza, 2012). The impact of the graduate mentor is necessary to guide students through the graduate school process, "devise a plan of study...expedite employment, research and publication, and timely completion” (p.217, Haro, 2004) and facilitate pathways to a career beyond the doctorate. Furthermore, mentors 
demystify graduate school, provide a broader understanding of career paths and build networks across academia to bridge barriers they may experience (Luna \& Prieto, 2009).

In addition, Latinx students persist through more holistic approaches to their graduate experience that build upon the work aimed at increasing their undergraduate success. When focusing on the career paths of Latinx students, the social support, academic support and financial support emerge as dominant themes that facilitate positive outcomes (Sandoval-Lucero, Maes, \& Chopra, 2011). The combination of these three thematic areas of support are strengthened with increased interactions between Latinx students and the university faculty and staff, which become essential relationships to build positive campus climates (Hurtado \& Ponjuan, 2005).

The dearth of literature on career outcomes for Latinx doctorates and the scarce research for all career outcomes for doctorates is expressed in the need to develop new studies (Denecke, Feaster, \& Stone, 2017) that address this gap in the literature. The relational aspect—the personalismo - of the graduate experience is the most salient measure of success and manifests itself between peers, faculty, family and program (Tijerina \& Deepak, 2014). The psychosociocultural (PSC) framework integrates three major dimensions of Latinx students' experience that can be both points of contention and facilitators of success; and provides a framework of understanding the Latinx educational experience (Gloria \& Rodriguez, 2000). The PSC approach is also relevant to Latinx doctoral students because it leverages a holistic framework for managing, navigating and seeking solutions to the dissonant experiences within each of these three areas during graduate school (Gloria \& Castellanos, 2003; Castellanos \& Gloria, 2007). Curtin, Malley and Stewart (2016) developed a study that builds upon the PSC framework by looking at three different types of mentoring (instrumental, pyschosocial and 
sponsorship) and their implications for career self-efficacy. They found that there were significant race gender differences for URM compared to non-URM and split by gender $(p<$ .05 ), and that URM women were had significantly less interest in an academic faculty position in comparison to all other race-gender groups $(p<.01)$. Furthermore, they conclude that early stage mentoring is important and that their career goals are influenced by all three types of mentoring.

A closer look at the literature on the graduate experience identifies a number of factors that influence for career pathways. Throughout the literature the most prevalent contributor to successful graduate experiences and transition to a career remains the role of mentorship (Solem, Kollasch, \& Lee, 2013; Ocasio, 2014; Choudhary \& Jesiek, 2015; Stroup \& Kuk, 2015). The mentoring relationship is key for all students; however for Latinx students it provides a foundation to support the myriad of obstacles facing students (Frank, 2015; Heflinger \& Doykos, 2016). The mentor's role is to help students develop their research agenda and enhance their market-readiness. However, Latinx students face an additional challenge because many times their mentors do not have the expertise within the context of their chosen area of study, particularly with in the diaspora of Latinx culture and literature (Frank, 2015). This further exemplifies the implications of the marginal representation of Latinx faculty within the academy (Ponjuan, 2012; Ramirez, 2017).

The formation of academic identities for Latinx doctoral is also an important area of development because it is influenced by a number of factors connected to the access of both social capital and institutional resources (Espino, Muñoz, \& Kiyama, 2010; Cassuto, 2015; Tran, Jean-Marie, Powers, \& Sanders, 2016). Some of these areas described in the literature to support the career pathway are inclusive of financial aid, faculty mentors, curriculum, professional 
development opportunities and interdisciplinary skill development. Social capital is inclusive of the representation of Latinx faculty mentors, engagement with Latinx staff, the cultural relevancy of programming that addresses the holistic student experience and other social networks within the institution (Tran et al., 2016).

Given the changes in the academic job market, to be more competitive and to provide broader inquiry to a particular discipline, more attention is needed in the development of interdisciplinary skill sets by seeking cross disciplinary collaborations and more formally documenting these specializations through graduate certificates (Solem et al., 2013; Smith, 2015; Heflinger \& Doykos, 2016). More recently, Cassuto (2015), Smith (2015) and Patel (2017) have described the emergence of curricular changes that support the development of professional identities, integrating professionalism (e.g., of the discipline, of graduate education), pedagogical training, coursework and re-thinking what is needed to successfully meeting the expectations of the job market upon completion of the PhD regardless of career goal. As these curricular discussions have shifted activities at the department level, graduate schools and universities as a whole are focusing on professional development, which include areas teaching, grant writing, publishing, career planning, management, communications, internships and public speaking (Heflinger \& Doykos, 2016, Denecke et al., 2017). Accessibility and availability of these institutional resources have a measurable impact on student preparedness for the academic and non-academic job market (Heflinger \& Doykos, 2016; Tran et al., 2016). Lastly, the role of financial support (Sandoval-Lucero et al., 2011; Tran et al., 2016) in terms of graduate fellowships that facilitate access to the doctorate and funded opportunities to present at conferences, engage in funded independent research, gain additional research expertise and attend professional development trainings not offered by the institution. 


\section{Research Methods}

Research Design

This research was designed using a case study methodology (Yin, 2002, Stake 1995) and relies on an in-depth examination of a unit within a system in which the phenomena of interest is occurring. This methodological framework was used because it aligns with the critical empirical criteria of the phenomena being studied. According to Yin (2002), the critical components of an empirical case study are those that "investigate a contemporary phenomenon within its real-life context, especially when the boundaries between phenomenon and context are not clearly evident." (p. 13). The doctoral education process is a complex and context-driven phenomena in which students' experiences are tightly intertwined with advisors, departments and institutional characteristics, therefore following the chain of reasoning consistent with a case study (Yin, 2002).

Based on a preliminary set of propositions to understanding Latinx pathways to careers, this paper relies on a single-case design (Yin, 2002) by restricting the unit of analysis to one institution, while attempting to capture the departures from generalities that exist within individual disciplines - a hallmark of doctoral education (Gardner, 2009). This approach was used for two reasons congruent with case-study methodology. First, this is a critical case as it is situated within one of the largest providers of doctoral education in the United States. This institution provides a critical mass of Latinx students and graduates to aid analysis. The institution is also unique for its consistent focus on collecting and maintaining several datasets related to the experience and outcomes of Latinx doctoral graduates. Secondly, the approach relies on this single case as a revelatory case. The study of the experiences and outcomes of Latinx students is severely lacking (Haro, 2004; Sandoval-Lucero et al., 2011; Shueths \& 
Carranza, 2012; Ramirez, 2017), especially in the context of using institutional data and indicators to provide a more aggregate view of phenomena (Rochin \& Mello, 2007). The outlined rationale provides critical support for the choice to focus on a single institution. Context

The Rackham Graduate School at the University of Michigan (U-M) is comprised of over 8,300 students who are enrolled in graduate departments in 18 of the 19 schools and colleges. According to The Carnegie Classifications of Institutions of Higher Education, the U-M's basic classification is Doctoral Universities: Highest Research Activity. The research mission of the graduate school has a long-standing history, with the first master's degree conferred in 1849 . The first PhDs were awarded in 1876, which were the first PhDs awarded by a public university in the United States. In 1935, the graduate school received its namesake with a $\$ 2.5$ million donation for the land and the construction of the current 155,410 square foot building in addition to a generous donation by Horace and Mary Rackham, a $\$ 4$ million endowment to fund research and fellowships. This endowment supports a large portion of doctoral student fellowships, research experiences, conference travel and professional development activities. The 2016 enrollment numbers included 5,313 doctoral students, $42 \%$ female, $35 \%$ international and of the U.S. citizen and permanent resident domestic students-6\% Black, 9\% Asian American, 10\% Latinx, $4 \%$ two or more, $66 \%$ White. Each year over 800 doctoral degrees are awarded, making the Rackham Graduate School the number one producer of the $\mathrm{PhD}$, ranked first in URM $\mathrm{PhD}$ graduates and ranked third in graduating Latinx PhDs in the U.S. (NCES, 2016). The median time to degree is 5.57 years for the $\mathrm{PhD}$, and students' 10 -year completion rate is at $75 \%$ with the current cohort trending towards $80 \%$.

Sample 
Two primary data sources are used to frame and contextualize the experiences and career trajectories of domestic Latinx students. First, a survey of doctoral graduates is used to understand their mentoring, career preparation and overall academic experiences. Participants in this dataset are doctoral graduates from August 2012 to May 2016. This sample is comprised of 4,205 students with a $74 \%$ overall response rate for a total of 3,809 responses. This survey is administered after every graduating term to all Rackham doctoral graduates with a conferred degree. (Note: Graduates were only given the choice to self-identify as Hispanic in the survey used in this paper, however the researchers made the choice to use the term Latinx to describe these graduates as the most inclusive description of this category of students.) This dataset provides an overview of influential activities and interactions of Latinx students as part of their graduate experience. The second set of data is drawn from an institutional dataset containing career outcome data for all graduates since August, 1998. This database includes 13,416 graduates and has at least one year of data for $90 \%$ of graduates. Within this sample, $10 \%(1,431)$ are federally designated underrepresented minorities (URMs). Of these URMs, 46\% (643) self-reported their ethnicity as Hispanic. These data contain job titles, employers and location. For each job title, a determination is made to code each job under a job type, as described in Table 1, to facilitate analyses and reporting. This dataset provides a unique set of career outcomes and pathways for Latinx graduates at key career markers - 11, 5 and 10 years post-graduation, which encompass postdoctoral, tenure-track and other career paths.

[Insert Table 1 here]

Latinx students are identified through self-report in both instruments. It is worth noting a sharp increase in the number of Latinx identified students after 2007. This rise is largely due to a change in federal reporting requirements implemented in 2007 regarding the classification of 
students reporting multiple races/ethnicities, which increased the number of self-reported Latinx students.

\section{Results}

Survey of Doctoral Graduates

Five measures of the student experience are drawn from the survey are important to highlight because they represent the climate and context of the Rackham graduate experience and inform the impact of various initiatives specific to Latinx and other underrepresented graduate students. The academic experience satisfaction, identifying a mentor to guide your research, professional development, and career preparedness are single items scaled from 1 to 5, with 5 indicating a high level of satisfaction during the graduate's doctoral career. The quality of mentoring scale is a composite scale comprised of seven items asking about the quality of various aspects of mentoring including mentoring during the dissertation process, and mentoring about career and professional development. The scale is scored from one to five, with five indicating an excellent rating for quality of mentoring.

The results presented in Table 2 show an overwhelmingly positive experience by graduates across all five areas of graduate education experience with overall mean responses ranging from 3.7 to the highest at 4.21 . Further probing by broad disciplinary areas shows remarkably consistent results across all disciplines, in particular the high satisfaction with their overall academic experience and career preparedness with means ranging from 4.09 to 4.23 . Further exploration of these differences across years, including both overall means and broad discipline specific-means found no meaningful differences across the last five years.

[Insert Table 2 here] 
These five measures demonstrating a high level of satisfaction by graduate students with their academic experiences is further supported by the academic outcomes identified in Tables 3 and 4, which document the numbers of scholarly publications and presentations. When comparing the numbers of publications from 2007-2011 to 2012-2016, there has been a noticeable increase in publications across all disciplines. Further analysis indicates that another $57 \%$ of all graduates have another one to three additional publications currently under review. In addition, $68 \%$ of graduates have given four or more scholarly presentations during graduate school. The most significant results here are the disparities between disciplines that have given six or more presentations, in the biological and health sciences and physical sciences and engineering are $32 \%$ and $36 \%$ respectively in comparison to $56 \%$ in the social sciences and $54 \%$ of students in the humanities and the arts.

[Insert Tables 3 and 4 here]

\section{Career Outcomes}

The career outcomes in this dataset contain data for graduates from August 1999 to August 2016. These data contain standard demographic information such as gender and race/ethnicity as well as information about broad disciplines matching those reported in the doctoral graduate survey. The two datasets are synched by demographics and those graduates earning a doctorate. The career outcomes data, however, covers a longer horizon of graduates and thus allows for further probing of career trajectories and observations of whether changes exist by demographic indicators.

Table 5 summarizes the number of total graduates for which at least one year of data exists. As with previous data, the numbers are disaggregated by overall disciplines. In this case, the numbers are further disaggregated by Latinx, other underrepresented minorities and other 
domestic graduates. International graduates are excluded from this analysis because the foundation of literature regarding racial categories primarily references the experiences of domestic students and graduates. (Note: Domestic students in this dataset are defined as being U.S. citizens, permanent residents, or deferred action for childhood arrivals.)

[Insert Table 5 here]

Latinx students and graduates in the sample are roughly proportionally represented in the biological and health sciences and the humanities. In physical sciences and engineering, however, there is clearly an underrepresentation of Latinx graduates with only $24 \%$ compared to $34 \%$ of all domestic graduates. The opposite effect is observed in the social sciences with $28 \%$ of all domestic and Latinx graduates at $38 \%$. These patterns are somewhat representative of overall URM representation across disciplines.

To observe career trajectories, milestone years were selected to facilitate analysis. The first year of graduation is critical to report as it establishes the beginning of a graduate's career and sets typical pathways depending on starting points. The second period is year five because it is largely a pre-tenure marker. Additionally, previous analyses of this data have shown year five as a critical year when postdoctoral/research fellow percentages decrease and faculty positions increase. The latest milestone observed is ten years post-graduation to get a sense of long-term trends that might be present. The 10-year marker provides sufficient horizons for graduates to settle into careers and move into tenured-track positions or have achieved a tenured faculty position if an academic path is pursued.

Several patterns were observed that are worth highlighting in Table 6. First, beginning with tenured-track positions, the data show a clear movement towards this academic path at year five, and another decisive - albeit smaller, movement towards this career by year 10. The pattern 
is consistent for Latinx, other URMs, and the rest of the domestic population. It can be reasonably inferred that a significant number of graduates who begin in a postdoctoral fellow position will eventually find their way onto a tenure-track faculty position. Overall, this pattern holds with $52 \%$ of Latinx graduates, $48 \%$ of other URMs, and $40 \%$ of all other domestic graduates holding tenure-track position in year 10 . The overall numbers clearly point to a consistent trajectory towards tenure-track faculty careers. The fact that a larger proportion of Latinx graduates are in these positions long-term provides evidence that supports an assertion that the initiatives and efforts by the graduate school and its programs are helping these graduates seek the same opportunities as their peers.

[Insert Table 6 here]

Another observation indicates that some of these differences are present because of disciplinary patterns, and the overrepresentation of Latinx graduates within certain disciplines as aggregated in this study. Table 7 explores this assertion by breaking down the change from year 1 to year 10 percentages within each demographic by job category and division and provide the most insight into the career pathways of graduates and highlight the stark differences across overall disciplines.

[Insert Table 7 here]

Within the social sciences and the humanities and the arts (HA), graduates begin their careers in tenure-track positions at respective rates of 32\% and 37\%-especially high numbers compared to the $6 \%$ and $7 \%$ rates found in the biological and health sciences (BHS) and physical sciences and engineering (PSE) disciplines respectively. The customary postdoctoral fellowship takes the place of these positions in these disciplines with 60\% in BHS and 40\% in PSE beginning their careers in this setting. The results are striking by year 10 - while $73 \%$ of Latinx 
graduates are in tenure-track careers in the HA, only $40 \%$ of other URMs and $53 \%$ of other domestic graduates are in this career track.

In the PSE, the pattern is somewhat reversed. Only $19 \%$ of Latinx graduates are in tenure-track settings by year 10 , but $37 \%$ of other URMs and $26 \%$ of other domestic graduates are placed in this setting. An alternative explanation of these numbers is that Latinx graduates career placement after 10 years reflects strong disciplinary preferences. For Latinx STEM graduates the preference seems to be for "Business/Medical/Other" settings where outcomes indicate $46 \%$ in BHS and 55\% in PSE. Additionally, a significant number of graduates in the other URM and other domestic categories are also placed in the "Business/Medical/Other" setting, however, Latinx representation is proportionally higher. In comparison, in the social sciences and the humanities the majority of Latinx graduates are also placed in tenure-track positions in significantly higher numbers than their domestic and URM peers. This is the overwhelming career path followed by all social science and humanities graduates, and so the career placement of Latinx graduates, although significantly higher, is consistent with disciplinary preferences.

It is well known that disciplinary differences are dominant in doctoral education (Gardner, 2008, 2010) and those effects are clearly present here. From the perspective of Latinx career development after completing a doctoral, the data consistently shows they follow disciplinary trends in proportionally higher number than their peers. Whether this is an institutional effect, or an effect of a highly-selective doctoral institutional is a question that needs further exploration. These data, however, indicate the need to understand the aspects of the educational environment that help Latinx and other URM students prepare for their careers. 
Furthermore, these trends also suggest that the programs and practices of the graduate school are, at the very least, aligned with preparation for academic career outcomes.

\section{Overview of Rackham Graduate School Programs}

At the Rackham Graduate School there are a number of programs that have been developed to increase the success of students' graduate experiences. Beyond programming, policy and practice are also a part of the holistic approach designed to have a positive impact on the student. The following programs, policies and practices are directly connected to mentoring, professional and academic skill development, student support, career preparation and institutional engagement. Mentoring Others Results in Excellence (MORE)

MORE is a program centered on engaging faculty and graduate students around developing positive mentoring practices to improve retention and academic success. The core of this program is a 10-member faculty committee whom are experts in practice on mentoring representing a wide range of academic disciplines. MORE provides two different types of workshops, one called the Departmental Mentoring Workshop and another called the Mentoring Plan Workshop. The departmental workshop is given upon request, limited to department faculty, and based on the norms of mentoring within a specific field, a range of strategies are explored The results are striking by year 10 - while $73 \%$ of Latinx graduates are in tenure-track careers in the HA, while only $40 \%$ of other URMs and $53 \%$ of other domestic graduates within the discipline — some of the topics covered in this workshop include diversity, professional development, developing two-way conversations and the value of integrating a written individual mentoring plan. The Mentoring Plan Workshop is designed for faculty and students—-mentors and mentees. During this workshop, held three times a year, students work with their faculty 
mentor to develop the individual mentoring plan that covers their academic and career interests and are encouraged to revise this plan annually.

Faculty Allies for Diversity in Graduate Education

This program is designed to identify a faculty member in a department who has demonstrated a commitment to diversity, equity and inclusion to serve as a liaison for their faculty peers and students in collaboration with the graduate school. These faculty allies work collaboratively to address issues and plan actions steps around diversity initiatives which include recruitment, admissions, climate, retention and completion. These "go-to" persons within a department raise awareness and support educational and professional development workshops that allow students to explore and address concerns within their departments. Furthermore, these efforts are supported through special meetings to learn about effective practices and eligibility to apply for two-year diversity grants that support their work and initiatives.

\section{Rackham Program Review}

The purpose of program review is to collaboratively engage with departmental leadership to identify opportunities for improving graduate education by sharing ideas, current research and promising practices on graduate education. Programs are reviewed on a five-year cycle and conversations are data-driven. The data compiled provides a longitudinal review of select indicators (e.g., admissions, enrollment, degrees, demographics, placement) as well as student survey feedback. The data are compiled by the graduate school provides comparative context by providing multiple levels of data, which includes the individual graduate program, disciplinary division, school/college and aggregated at the graduate school. Using this data, the departments and the graduate school hold a series of meetings to discuss the future of the program, 
recruitment strategies, advising and mentoring, completion, placement, career preparation and student research productivity. The goals of these discussions with program leadership are to better understand a graduate program's recent performance and challenges as well as explore future directions for the graduate programs. At the end of this process the graduate school provides a letter summarizing the findings of the review, a set of recommendations and programs provide a written response to address the recommendations.

\section{Rackham Merit Fellows (RMF) Program}

The RMF Program provides students with five years of funding support and is complimented by a set of programming that supports specialized academic, social, cultural and professional development opportunities throughout their graduate experience. The RMF enters its fourth decade of sustained academic excellence and inclusiveness of students from the broadest array of diverse educational, cultural, geographic and familial experiences. The RMF program also uses a cohort model, incoming students participate in RMF Connection (formerly known as Summer Institute-SI) to engage in academic intensive and transition focused workshops, in addition to activities aimed at cultivating an interdisciplinary community. The complimentary RMF programming is an essential component for student success beyond the financial support, because these students benefit from individualized support, intensive writing retreats, faculty and alumni panels, social/cultural activities and mentoring.

\section{Professional Development}

The array of professional development activities is codified at Rackham into three key areas: core skill development, career exploration and job search skill development. Within these key areas are opportunities for students to participate in interdisciplinary research groups, 
internships, career immersive experiences, certificate programs, develop strategies, and engage in a wide range of training (e.g., communication, conflict resolution, bias intervention) to maximize their graduate experiences. In addition, this work includes collaborative partnerships with multiple centers on campus (e.g., teaching and technology, career, research on learning and teaching, statistical consultation and research, writing) to address the academic and market needs of graduate students.

\section{Comprehensive Funding of Graduate Experiences}

One of the unique aspects of the doctoral experience at Rackham is the fully funded model, providing five years of funding, which includes health care coverage. To address the expected academic experiences, students are provided with annual conference travel grants, professional development grants, pre-candidacy and candidacy graduate student research grants and international research awards. In addition, students are eligible for a number of other awards that support their personal needs beyond that fall outside the scope of their graduate program.

\section{Limitations}

Despite the analytical framework, research design and analysis of scarce data points related to career outcomes, a number of limitations still exist within this study. The most significant issues within this study are the generalizability and internal validity in this discussion. Limited Availability of Demographic Data

The survey of doctoral graduates contains a number of indicators about the doctoral experience giving insight into experiences with mentors, career expectations and impressions of types of experiences provided by programs to help graduates move into a career of choice. The summarization of several positive trends reported by graduates, the analysis is restricted to disaggregation by discipline, but are unable to provide insights about any potential differences 
existing between demographics such as race, ethnicity and gender since the instrument is administered anonymously and no demographic information is collected. Previous studies have also shown differentially negative experiences in peer and departmental environments for URMs compared to their peers (Turner \& Thompson, 1993). Additional gaps identified by other surveys (NSF, 2014, 2015) that show first-generation college graduates receiving doctorates as more likely to hold a high level of financial debt upon graduation (p. 12) are examples of data not represented in this study, which could influence career outcomes. Given these gaps, it's reasonable to expect Latinx graduates' doctoral experience might have additional variables influencing their experience and career outcomes in this study. Although these gaps are not currently available to further explore, there is a likelihood that these differential variables are being addressed within their graduate experience at least regarding the lack of visible gaps existing within academic career outcome categories. Future implementations of the survey will be linked to demographic markers and should allow this assertion to be validated when exploring future graduating cohorts.

Small Disaggregated Sample Size

In the case of the second dataset employed in this study, a different limitation arises. Demographic data are widely available in this data, but despite a multiyear sample that includes over 13,000 graduates over a 17-year period, the number of graduates used for this analysis quickly dwindles when demographics and disciplines are accounted for. Only $11 \%$ of our sample of graduates $(1,431)$ is considered Latinx. Within this sample, numbers differ across disciplines with graduates strongly represented in the social sciences (43\%), but often lacking representation in the humanities $(15 \%)$ and the biological and health sciences (18\%). This presents analytical problems when looking at cross-sectional and departmental outcomes when some years, fewer 
than 10 graduates are present in particular disciplines. Given our high national ranking of graduating Latinx PhDs, the relative small numbers of graduates that are Latinx make analysis at any single institution difficult. Using national datasets and surveys (i.e., SED) might eventually make these analyses more feasible, but the lack of demographic data combined with longitudinal career outcomes made such analyses unfeasible for this study.

Connecting Graduate Experiences to Career Outcomes

A salient issue in this study is the lack of a direct correlation between the student experience and the various observed career outcomes. While the impact of a holistic approach regarding the system of reforms on the doctoral education process as a driver for improved completion and successful pursuit of tenured-track faculty careers, this is not equivalent to assuming a homogenous experience among Latinx graduates, other under-represented minorities, and domestic graduates as a whole. This study relies on the overall measures of mentoring quality, departmental support and perceptions of career preparedness to suggest the presence of support mechanisms to prepare graduates to pursue desired careers. Measures of satisfaction suggest an overall positive climate; however as aforementioned, these measures are not broken down by demographics nor linked directly to the measures of career outcomes due to the anonymous nature of the survey of graduates. Furthermore, due to the inherent time-lag between long-term career outcomes and graduation, linkages across datasets are most appropriate at the early career levels since some of the described initiatives have been implemented within the last 10 years. Therefore, outcomes of graduates over 10 years, as reported in this study, reflect a different environment than that being experienced by the most recent graduates.

\section{Discussion}


This case study provides an overview of a graduate school that has taken a holistic approach to graduate education and the effect it has on its graduate students, with particular attention to the career outcomes on Latinx graduates. When looking at the career outcomes of Latinx doctoral students at the Rackham graduate school, the resulting data indicated that Latinx doctoral graduates persist at equal or greater rates in compared to their URM and other domestic counterparts across career outcome categories. Furthermore, given the literature on Latinx academic career pathways, these data describe a different outcome than is evidenced in the larger body of research. Latinx students in this case study as a whole persist through tenure-track at a greater rate $+4 \%$ greater than other URMs and $+12 \%$ higher than other domestic graduates 10 years after completion. Further analysis of these tenure-track outcomes after 10 years by discipline (humanities and the arts, $+33 \% \mathrm{URM} /+20 \%$ domestic; social sciences, $+10 \%$ $\mathrm{URM} /+11 \%$ domestic; biological and health sciences, $-3 \% \mathrm{URM} /-2 \%$ domestic; physical sciences and engineering, $-18 \% \mathrm{URM} /-7 \%$ domestic) indicate that there are more differences within disciplines. Within the biological and health sciences marginal differences exist between Latinx; however when looking at the differences within the physical sciences and engineering there are indications that Latinx students are not persisting at the same rate, but that they are disproportionately in other educational settings in comparison to their URM (+21\%) and domestic $(+17 \%)$ counterparts. Another considerable result is the Latinx tenure-track outcomes in the social sciences and even more noteworthy are the sizeable differences within the humanities and the arts. These varied results suggest that there are some components to the holistic approach at the University of Michigan that significantly prepares Latinx doctoral students for tenure-track positions within the humanities, arts and social sciences, but these approaches may not be consistent across the sciences. 
This study provides a rationale to review policy, practices and points of intervention as they relate to these factors that influence success for Latinx students across disciplines. As aforementioned, there are some tailoring of programs to disciplines, but these data may indicate that there either exists a gap in programming within the sciences or a need to further specialize the approaches in these disciplines. The number of presentations and papers published in combination with professional development and career preparedness, supports an assertion that these graduates are also more competitive in the academic marketplace. Based on the career outcomes, survey data and the analysis of programs within this case study further suggest that the implications of these collective efforts around mentoring, funding, and professional development specifically have a positive outcome for Latinx students' academic career outcomes.

The implications of this study for future research on graduate career outcomes given these results is significant to future programming, mentoring and professional development. As much as the negative gaps exist in the natural sciences and engineering, there is clearly a need to understand the substantial positive outcomes in the humanities and social sciences for Latinx graduates in comparison to their domestic peers. The findings in this study significantly support the need to understand further the doctoral experiences of Latinx students while in graduate school that project their greater likelihood for tenure track success in the following categories: pre-doctoral educational experiences, academic and professional development preparation, their early career and pre-tenure experiences, and the influence of identity (e.g. gender, generational status and culture) throughout their career pathway.

\section{Conclusion}

This case study has resulted in the first documentation of the Latinx doctoral career pathway and outcomes a decade after graduation; the identification of several contextual 
components to the graduate experience and unique institutional opportunities for students during their doctoral education; and the practical impact of tracking the career placements of Latina/o doctoral students. This study provides a foundation for a number of strategies that have a positive impact for Latinx graduate students and should be considered by graduate education practitioners and faculty—mentors and advisors. The increasing Latinx demographic in higher education is outpacing the stagnant representation of Latinx faculty and administrators, hence positioning the Latinx $\mathrm{PhD}$ as the most significant indicator for change in higher education. Therefore, further documentation and examination of the Latinx doctoral career pathway is strategically crucial to understanding many of the educational challenges and issues facing the Latinx community. 


\section{References}

Cassuto, L. (2015). The graduate school mess: What caused it and how we can fix it? Cambridge, MA: Harvard University Press.

Castellanos, J., Gloria, A.M. \& Kamimura, M. (2006) The Latina/o pathway to the PhD: Abriendo caminos. Sterling, VA: Stylus Publishing, LLC.

Castellanos, J. \& Gloria, A.M. (2007). Research considerations and theoretical application for best practices in higher education: Latina/os achieving success. Journal of Hispanic Higher Education, 6(4), 378-396.

Choudhary, N. \& Jesiek, B.K. (October, 2015). Engineering Ph.D. students' career preference: Levels, changes, and the role of advisors. Paper presented at Frontiers in Education Conference, El Paso, TX.

Curtin, N., Malley, J. \& Stewart, A.J. (2016). Mentoring the next generation of faculty: Supporting academic career aspirations among doctoral students. Research in Higher Education, 57(6), 714-738.

Denecke, D., Feaster, K., \& Stone, K. (2017). Professional development: Shaping effective programs for STEM graduate students. Washington, DC: Council of Graduate Schools.

DiMaria, F. (2015). Mellon foundation: Supports for Latino doctoral students in humanities. The Hispanic Outlook in Higher Education, 25(13), 16-18.

Espino, M.M., Muñoz, S.M., \& Kiyama, J.M. (2010). Transitioning from doctoral study in the academy: Theorizing trenzas of identity for Latina sister scholars. Qualitative Inquiry 16(10), 804-818.

Gardner, S. K. (2008). "What's too much and what's too little?" The process of becoming an independent researcher in doctoral education. The Journal of Higher Education, 79, 326350.

Gardner, S. K. (2010). Contrasting the socialization experiences of doctoral students in high and low-completing departments: A qualitative analysis of disciplinary contexts at one institution. The Journal of Higher Education, 81(1), 61-81.

Gloria, A. M., \& Castellanos, J. (2003). Latino/a and African American students at predominantly White institutions: A psychosociocultural perspective of educational interactions and academic persistence. In J. Castellanos \& L. Jones (Eds.), The majority 
in the minority: Retaining Latinalo faculty, administrators, and students (pp. 71-92). Sterling, VA: Stylus.

Gloria, A. M., \& Rodriguez, E. R. (2000). Counseling Latino university students: Psychosociocultural issues for consideration. Journal of Counseling and Development, $78,145-154$.

Haro, R. (2004). Programs and strategies to increase Latino students' educational attainment. Education and Urban Society, 36(2), 205-222.

Haro, R. \& Lara, J. F. (2003) Latinos and administrative positions in American higher education. In J. Castellanos and L. Jones. (Eds.) The majority in the minority: expanding the representation of Latina/o faculty, administrators and students in higher education (pp.153-165). Sterling, VA: Stylus Publishing.

Heflinger, C.A. \& Doykos, B. (2016). Paving the pathway: Exploring student perceptions of professional development preparation in doctoral education. Innovative Higher Education, 41, 343-358.

Huber, L. P., Huidor, O., Malagon, M., Sanchez, G., \& Solorzano, D. (2006). Falling through the cracks: Critical transitions in the Latino/a educational pipeline. Los Angeles: University of California, Los Angeles, Chicano Studies Research Center.

Hurtado, S., \& Ponjuan, L. (2005). Latino Educational Outcomes and the Campus Climate. Journal of Hispanic Higher Education. 4(3). 235-251.

Luna, V. \& Prieto, L. (2009). Mentoring affirmations and interventions: A bridge to graduate school for Latina/o students. Journal of Hispanic Higher Education, 8(2), 213-224.

National Center for Education Statistics (2013). U.S. Department of Education, National Center for Education Statistics, Integrated Postsecondary Education Data System (IPEDS), Winter 2011-12, Human Resources component, Fall Staff section. (This table was prepared July 2012.) Retrieved from https://nces.ed.gov/programs/digest/d13/tables/xls/tabn314.40.xls

National Science Foundation, National Center for Science and Engineering Statistics. 2015. Doctorate Recipients from U.S. Universities: 2014. Special Report NSF 16-300. Arlington, VA. Available at http://www. nsf.gov/statistics/2016/nsf16300/. 
National Science Foundation, National Center for Science and Engineering Statistics. 2016. Doctorate Recipients from U.S. Universities: 2015. Special Report NSF 17-306. Arlington, VA. Available at www.nsf.gov/statistics/2017/nsf17306/.

Ocasio, K.M. (2014). Nuestro camino: A review of literature surrounding the Latino teacher pipeline. Journal of Latinos and Education, 13(4), 244-261.

Patel, V. (2017, January 29). Opening doors for the Ph.D.. The Chronicle of Higher Education. Retrieved from http://chronicle.com

Ponjuan, L. (2012). The missing piece to Latino student success: Recruiting and retaining Latino faculty members. The Hispanic Outlook in Higher Education, 22(19), 16-19.

Ramirez, E. (2017). Unequal socialization: Interrogating the Chicano/Latino(a) doctoral education experience. Journal of Diversity in Higher Education, 10(1), Mar 2017, 25-38.

Rochin, R. I. \& Mello, S. F. (2007). Latinos in science: Trends and opportunities. Journal of Hispanic Higher Education, 6(4), 305-355.

Sandoval-Lucero, E., Maes, J.B., \& Chopra, R.V. (2011). Examining the retention of nontraditional Latino(a) students in a career-based learning community. Journal of Hispanic Higher Education, 10(4), 299-316.

Shueths, A.M. \& Carranza, M.A. (2012). Navigating around educational road blocks: Mentoring for pre-k to 20+ Latino/a students. Latino Studies, 10(4), 566-586.

Smith, S. (2015). Manifesto for the humanities: Transforming doctoral education in good enough times. Ann Arbor, MI: University of Michigan Press.

Solem, M., Kollasch, A. \& Lee, J. (2012). Career goals, pathways and competencies of geography graduate students in the USA. Journal of Geography in Higher Education, 37(1), 92-116.

Stake, R.E. (1995). The art of case study research. Thousand Oaks, CA: Sage Publications, Inc.

Stroup, L.M. \& Kuk, L. (2015). Nursing as a career choice by Hispanic/Latino college students: A multi-institutional study. Journal of Nursing Education, 54(9), 583-588.

Tijerina, M. \& Deepak, A.C. (2014). Mexican American social workers' perceptions of doctoral education and academia. Journal of Social Work Education, 50(2), 365-378. 
Tran, N.A., Jean-Marie, G., Powers, K., Bell, S. \& Sanders, K. (2016). Using institutional resources and agency to support graduate students' success at a Hispanic serving institution. Education Sciences, 6(28), 1-14.

Turner, C. S. V., \& Thompson, J. R. (1993). Socialization women doctoral students: Minority and majority experiences. The Review of higher Education, 16(3), 355-370.

U.S. Department of Education, National Center for Education Statistics, Integrated Postsecondary Education Data System (IPEDS), Fall 2014 and Fall 2015, Completions component. (This table was prepared September 2016.) https://nces.ed.gov/programs/digest/d16/tables/dt16_324.25.asp?current=yes

Yin, R.K. (2002). Applications of case study research (2 ${ }^{\text {nd }}$ ed.) [Applied Social Research Methods Series Volume 34]. Thousand Oaks, CA: Sage Publications, Inc. 
Table 1

Overview of Career Outcomes Categories

\begin{tabular}{ll}
\hline Job Type & Description \\
\hline Tenure-Track & $\begin{array}{l}\text { Graduate works as a tenure-track faculty in an AAU } \\
\text { institution }\end{array}$ \\
Staff in other Educational Setting & $\begin{array}{l}\text { Graduate works in a University setting either as an } \\
\text { instructor, administrator, or staff member }\end{array}$ \\
Business/Medical/Other & $\begin{array}{l}\text { Graduate works within a business or corporation, a } \\
\text { government or national lab, a non-profit organization, a } \\
\text { medical setting, or another similar circumstance. }\end{array}$ \\
Freelance/Self-Employed/Artist/Independent Scholar & $\begin{array}{l}\text { Graduate is self-employed or conducts independent } \\
\text { research }\end{array}$ \\
Other Career Circumstance & $\begin{array}{l}\text { Graduate is currently unemployed, continuing } \\
\text { education, or not working due to family care or health } \\
\text { issues }\end{array}$ \\
Unknown & \begin{tabular}{l} 
No data is available for the graduate \\
\hline
\end{tabular}
\end{tabular}


Table 2

Survey of Doctoral Graduates 2012-2016

\begin{tabular}{|c|c|c|c|c|c|c|}
\hline $\begin{array}{l}\text { Area of Graduate } \\
\text { Experience }\end{array}$ & & $\begin{array}{l}\text { Biological and } \\
\text { Health Sciences }\end{array}$ & $\begin{array}{l}\text { Physical Sciences } \\
\text { and Engineering }\end{array}$ & $\begin{array}{l}\text { Social } \\
\text { Sciences }\end{array}$ & Humanities & $\begin{array}{l}\text { Whole } \\
\text { Sample }\end{array}$ \\
\hline \multirow{3}{*}{$\begin{array}{l}\text { Academic Experience } \\
\text { Satisfaction }\end{array}$} & Mean & 4.18 & 4.23 & 4.20 & 4.23 & 4.21 \\
\hline & S.D. & 0.88 & 0.85 & 0.87 & 0.90 & 0.87 \\
\hline & $\mathbf{N}$ & 658 & 1235 & 683 & 249 & 2840 \\
\hline \multirow{3}{*}{$\begin{array}{l}\text { Identifying a Mentor to } \\
\text { Guide Your Research }\end{array}$} & Mean & 3.95 & 4.04 & 3.88 & 3.85 & 3.96 \\
\hline & S.D. & 1.14 & 1.06 & 1.14 & 1.23 & 1.12 \\
\hline & $\mathbf{N}$ & 684 & 1274 & 735 & 262 & 2971 \\
\hline \multirow{3}{*}{$\begin{array}{l}\text { It's Quality of } \\
\text { Mentoring }\end{array}$} & Mean $^{a}$ & 3.89 & 4.00 & 3.86 & 3.81 & 3.93 \\
\hline & S.D. & 1.13 & 1.04 & 0.97 & 1.19 & 1.10 \\
\hline & $\mathbf{N}^{\mathbf{b}}$ & 4597 & 8995 & 4805 & 1745 & 19795 \\
\hline \multirow{3}{*}{$\begin{array}{l}\text { Professional } \\
\text { Development }\end{array}$} & Mean & 3.59 & 3.83 & 3.59 & 3.59 & 3.7 \\
\hline & S.D. & 1.28 & 1.14 & 1.25 & 1.29 & 1.22 \\
\hline & $\mathbf{N}$ & 693 & 1304 & 740 & 273 & 3026 \\
\hline \multirow[t]{3}{*}{ Career Preparedness } & Mean & 4.09 & 4.14 & 4.12 & 4.11 & 4.12 \\
\hline & S.D. & 0.84 & 0.79 & 0.81 & 0.84 & 0.81 \\
\hline & $\mathbf{N}$ & 697 & 1316 & 746 & 272 & 3047 \\
\hline
\end{tabular}

aPooled means and standard deviations derived from 9 separate items. ${ }^{\mathrm{b}}$ Since items are pooled and each item has a different number of respondents, the total $\mathrm{N}$ used to calculate pooled means and standard deviations is displayed. 
Table 3

Number of Scholarly Works That Have Been Published or Accepted for Publication

\begin{tabular}{|c|c|c|c|c|c|c|c|c|c|c|c|}
\hline & & \multicolumn{2}{|c|}{$\begin{array}{l}\text { Biological and } \\
\text { Health Sciences }\end{array}$} & \multicolumn{2}{|c|}{$\begin{array}{l}\text { Physical Sciences } \\
\text { and Engineering }\end{array}$} & \multicolumn{2}{|c|}{ Social Sciences } & \multicolumn{2}{|c|}{ Humanities } & \multicolumn{2}{|c|}{ Whole Sample } \\
\hline & & $\begin{array}{l}2007- \\
2011\end{array}$ & $\begin{array}{l}2012- \\
2016\end{array}$ & $\begin{array}{l}2007- \\
2011\end{array}$ & $\begin{array}{l}2012- \\
2016\end{array}$ & $\begin{array}{l}2007- \\
2011\end{array}$ & $\begin{array}{l}2012- \\
2016\end{array}$ & $\begin{array}{l}2007- \\
2011\end{array}$ & $\begin{array}{l}2012- \\
2016\end{array}$ & $\begin{array}{l}2007- \\
2011\end{array}$ & $\begin{array}{l}2012- \\
2016\end{array}$ \\
\hline \multirow{8}{*}{$\begin{array}{l}\text { \# of } \\
\text { Papers }\end{array}$} & 0 & $18 \%$ & $10 \%$ & $17 \%$ & $8 \%$ & $37 \%$ & $27 \%$ & $56 \%$ & $29 \%$ & $26 \%$ & $15 \%$ \\
\hline & 1 & $22 \%$ & $15 \%$ & $23 \%$ & $9 \%$ & $27 \%$ & $22 \%$ & $23 \%$ & $30 \%$ & $24 \%$ & $15 \%$ \\
\hline & 2 & $23 \%$ & $18 \%$ & $19 \%$ & $12 \%$ & $18 \%$ & $16 \%$ & $11 \%$ & $15 \%$ & $19 \%$ & $15 \%$ \\
\hline & 3 & $15 \%$ & $20 \%$ & $14 \%$ & $14 \%$ & $8 \%$ & $12 \%$ & $5 \%$ & $12 \%$ & $12 \%$ & $15 \%$ \\
\hline & 4 & $8 \%$ & $11 \%$ & $9 \%$ & $11 \%$ & $4 \%$ & $7 \%$ & $3 \%$ & $7 \%$ & $7 \%$ & $10 \%$ \\
\hline & 5 & $5 \%$ & $7 \%$ & $6 \%$ & $7 \%$ & $2 \%$ & $4 \%$ & $1 \%$ & $3 \%$ & $4 \%$ & $6 \%$ \\
\hline & $6+$ & $10 \%$ & $19 \%$ & $11 \%$ & $38 \%$ & $4 \%$ & $12 \%$ & $2 \%$ & $5 \%$ & $8 \%$ & $24 \%$ \\
\hline & $\mathbf{N}$ & 494 & 699 & 1011 & 1309 & 578 & 747 & 225 & 270 & 2328 & 3041 \\
\hline
\end{tabular}


Table 4

Number of Research or Scholarly Presentations

\begin{tabular}{lllllll}
\hline & & $\begin{array}{l}\text { Biological and } \\
\text { Health Sciences }\end{array}$ & $\begin{array}{l}\text { Physical Sciences and } \\
\text { Engineering }\end{array}$ & $\begin{array}{l}\text { Social } \\
\text { Sciences }\end{array}$ & Humanities & $\begin{array}{l}\text { Whole } \\
\text { Sample }\end{array}$ \\
\hline \# of & $\mathbf{0}$ & $5 \%$ & $4 \%$ & $2 \%$ & $2 \%$ & $4 \%$ \\
Presentations & $\mathbf{1}$ & $8 \%$ & $7 \%$ & $4 \%$ & $6 \%$ & $6 \%$ \\
& $\mathbf{2}$ & $14 \%$ & $12 \%$ & $7 \%$ & $8 \%$ & $11 \%$ \\
& $\mathbf{3}$ & $17 \%$ & $13 \%$ & $10 \%$ & $7 \%$ & $12 \%$ \\
& $\mathbf{4}$ & $14 \%$ & $15 \%$ & $10 \%$ & $10 \%$ & $13 \%$ \\
& $\mathbf{5}$ & $11 \%$ & $14 \%$ & $11 \%$ & $13 \%$ & $13 \%$ \\
& $\mathbf{6 +}$ & $32 \%$ & $36 \%$ & $56 \%$ & $54 \%$ & $42 \%$ \\
& $\mathbf{N}$ & 654 & 1215 & 672 & 244 & 2800 \\
\hline
\end{tabular}


Table 5

Number of Graduates by Overall Disciplines and Demographics

\begin{tabular}{llllll}
\hline & $\begin{array}{l}\text { Biological and Health } \\
\text { Sciences }\end{array}$ & $\begin{array}{l}\text { Physical Sciences and } \\
\text { Engineering }\end{array}$ & $\begin{array}{l}\text { Social } \\
\text { Sciences }\end{array}$ & Humanities & $\begin{array}{l}\text { Whole } \\
\text { Sample }\end{array}$ \\
\hline Latinx & 115 & 127 & 200 & 84 & 526 \\
Other URM & 116 & 147 & 365 & 90 & 718 \\
$\begin{array}{l}\text { Other } \\
\text { domestic }\end{array}$ & 1786 & 2832 & 2022 & 1247 & 7887 \\
N & 2017 & 3106 & & & \\
\hline
\end{tabular}


Table 6

Graduates by Job Type and Year

\begin{tabular}{|c|c|c|c|c|c|c|c|c|c|}
\hline & \multicolumn{3}{|c|}{ Year 1} & \multicolumn{3}{|c|}{ Year 5} & \multicolumn{3}{|c|}{ Year 10} \\
\hline & Latinx & URM & Domestic & Latinx & URM & Domestic & Latinx & URM & Domestic \\
\hline $\begin{array}{l}\text { Tenure-Track } \\
\text { Faculty }\end{array}$ & $21 \%$ & $22 \%$ & $17 \%$ & $41 \%$ & $41 \%$ & $32 \%$ & $52 \%$ & $48 \%$ & $40 \%$ \\
\hline $\begin{array}{l}\text { Postdoctoral } \\
\text { Fellowship }\end{array}$ & $34 \%$ & $32 \%$ & $32 \%$ & $10 \%$ & $10 \%$ & $11 \%$ & $1 \%$ & $2 \%$ & $3 \%$ \\
\hline $\begin{array}{l}\text { Other Educational } \\
\text { Setting }\end{array}$ & $13 \%$ & $12 \%$ & $15 \%$ & $17 \%$ & $13 \%$ & $16 \%$ & $16 \%$ & $15 \%$ & $16 \%$ \\
\hline $\begin{array}{l}\text { Business/Medical/ } \\
\text { Other }\end{array}$ & $17 \%$ & $18 \%$ & $22 \%$ & $21 \%$ & $24 \%$ & $30 \%$ & $27 \%$ & $28 \%$ & $33 \%$ \\
\hline Not Employed & $15 \%$ & $16 \%$ & $13 \%$ & $10 \%$ & $12 \%$ & $11 \%$ & $4 \%$ & $7 \%$ & $8 \%$ \\
\hline $\mathbf{N}$ & 526 & 718 & 7887 & 384 & 569 & 5877 & 154 & 249 & 2371 \\
\hline
\end{tabular}


Table 7

Career Outcomes by Demographic Group and Discipline

\begin{tabular}{|c|c|c|c|c|c|c|c|c|c|c|c|c|}
\hline \multirow[b]{2}{*}{ Latinx } & \multicolumn{3}{|c|}{$\begin{array}{c}\text { Biological \& Health } \\
\text { Sciences }\end{array}$} & \multicolumn{3}{|c|}{$\begin{array}{l}\text { Physical Sciences \& } \\
\text { Engineering }\end{array}$} & \multicolumn{3}{|c|}{ Social Sciences } & \multicolumn{3}{|c|}{$\begin{array}{c}\text { Humanities \& the } \\
\text { Arts }\end{array}$} \\
\hline & Y1 & Y5 & Y10 & Y1 & Y5 & Y10 & Y1 & Y5 & Y10 & Y1 & Y5 & Y10 \\
\hline Tenure-Track Faculty & $6 \%$ & $23 \%$ & $31 \%$ & $7 \%$ & $23 \%$ & $19 \%$ & $32 \%$ & $54 \%$ & $66 \%$ & $37 \%$ & $55 \%$ & $73 \%$ \\
\hline Postdoctoral Fellowship & $60 \%$ & $27 \%$ & $8 \%$ & $40 \%$ & $11 \%$ & $0 \%$ & $23 \%$ & $4 \%$ & $0 \%$ & $14 \%$ & $1 \%$ & $0 \%$ \\
\hline Other Educational Setting & $5 \%$ & $11 \%$ & $4 \%$ & $6 \%$ & $15 \%$ & $26 \%$ & $18 \%$ & $22 \%$ & $19 \%$ & $23 \%$ & $18 \%$ & $10 \%$ \\
\hline Business/Medical/Other & $14 \%$ & $31 \%$ & $46 \%$ & $33 \%$ & $42 \%$ & $55 \%$ & $12 \%$ & $11 \%$ & $12 \%$ & $12 \%$ & $9 \%$ & $13 \%$ \\
\hline Not Employed & $15 \%$ & $9 \%$ & $12 \%$ & $13 \%$ & $10 \%$ & $0 \%$ & $16 \%$ & $9 \%$ & & $14 \%$ & $16 \%$ & \\
\hline \multicolumn{13}{|l|}{ Other URM } \\
\hline Tenure-Track Faculty & $8 \%$ & $25 \%$ & $34 \%$ & $7 \%$ & $17 \%$ & $37 \%$ & $30 \%$ & $51 \%$ & $56 \%$ & $28 \%$ & $55 \%$ & $40 \%$ \\
\hline Postdoctoral Fellowship & $59 \%$ & $22 \%$ & $6 \%$ & $35 \%$ & $15 \%$ & $5 \%$ & $28 \%$ & $7 \%$ & $1 \%$ & $9 \%$ & $4 \%$ & $0 \%$ \\
\hline Other Educational Setting & $6 \%$ & $19 \%$ & $16 \%$ & $4 \%$ & $8 \%$ & $5 \%$ & $15 \%$ & $12 \%$ & $15 \%$ & $24 \%$ & $21 \%$ & $24 \%$ \\
\hline Business/Medical/Other & $17 \%$ & $32 \%$ & $38 \%$ & $35 \%$ & $43 \%$ & $45 \%$ & $12 \%$ & $19 \%$ & $24 \%$ & $16 \%$ & $8 \%$ & $20 \%$ \\
\hline Not Employed & $9 \%$ & $3 \%$ & $6 \%$ & $18 \%$ & $18 \%$ & $8 \%$ & $15 \%$ & $12 \%$ & $5 \%$ & $23 \%$ & $12 \%$ & $16 \%$ \\
\hline \multicolumn{13}{|l|}{ Domestic } \\
\hline Tenure-Track Faculty & $7 \%$ & $19 \%$ & $33 \%$ & $7 \%$ & $19 \%$ & $26 \%$ & $32 \%$ & $49 \%$ & $55 \%$ & $31 \%$ & $53 \%$ & $53 \%$ \\
\hline Postdoctoral Fellowship & $53 \%$ & $26 \%$ & $5 \%$ & $36 \%$ & $10 \%$ & $3 \%$ & $23 \%$ & $6 \%$ & $1 \%$ & $9 \%$ & $2 \%$ & $1 \%$ \\
\hline Other Educational Setting & $9 \%$ & $16 \%$ & $20 \%$ & $7 \%$ & $10 \%$ & $9 \%$ & $20 \%$ & $21 \%$ & $20 \%$ & $32 \%$ & $21 \%$ & $19 \%$ \\
\hline Business/Medical/Other & $18 \%$ & $31 \%$ & $35 \%$ & $36 \%$ & $46 \%$ & $51 \%$ & $13 \%$ & $16 \%$ & $19 \%$ & $13 \%$ & $14 \%$ & $20 \%$ \\
\hline Not Employed & $12 \%$ & $9 \%$ & $7 \%$ & $15 \%$ & $16 \%$ & $10 \%$ & $12 \%$ & $9 \%$ & $5 \%$ & $14 \%$ & $10 \%$ & $8 \%$ \\
\hline
\end{tabular}

